\title{
Article \\ Biomechanical Analysis of Clavicle Hook Plates with a Range of Posterior Hook Offsets Implanted at Different Acromion Positions in the Acromioclavicular Joint: A Finite Element Analysis Study
}

\author{
Li-Kun Hung ${ }^{1,+} \mathbb{D}$, Cheng-Hung Lee ${ }^{1,2,3,+}$ and Kuo-Chih Su $4,5,6, *(\mathbb{D})$ \\ 1 Department of Orthopedics, Taichung Veterans General Hospital, Taichung 407, Taiwan; \\ likun.hung@gmail.com (L.-K.H.); 298f@vghtc.gov.tw (C.-H.L.) \\ 2 College of Medicine, National Chung Hsing University, Taichung 402, Taiwan \\ 3 Department of Food Science and Technology, Hungkuang University, Taichung 433, Taiwan \\ 4 Department of Medical Research, Taichung Veterans General Hospital, Taichung 407, Taiwan \\ 5 Department of Biomedical Engineering, Hungkuang University, Taichung 433, Taiwan \\ 6 Department of Chemical and Materials Engineering, Tunghai University, Taichung 407, Taiwan \\ * Correspondence: kcsu@vghtc.gov.tw; Tel.: +886-4-23592525 (ext. 5153) \\ + These authors contributed equally to this work.
}

check for

updates

Citation: Hung, L.-K.; Lee, C.-H.; Su, K.-C. Biomechanical Analysis of Clavicle Hook Plates with a Range of Posterior Hook Offsets Implanted at Different Acromion Positions in the Acromioclavicular Joint: A Finite Element Analysis Study. Appl. Sci. 2021, 11, 11105. https://doi.org/ 10.3390/app112311105

Academic Editor: Toh Yen Pang

Received: 4 August 2021

Accepted: 19 November 2021

Published: 23 November 2021

Publisher's Note: MDPI stays neutral with regard to jurisdictional claims in published maps and institutional affiliations.

Copyright: (c) 2021 by the authors. Licensee MDPI, Basel, Switzerland. This article is an open access article distributed under the terms and conditions of the Creative Commons Attribution (CC BY) license (https:/ / creativecommons.org/licenses/by/ $4.0 /)$.

\begin{abstract}
The clavicle hook plate is commonly used in acromioclavicular injuries; however, the biomechanical effect of the posterior hook offset and hook position is unclear. This study applied a finite element analysis (FEA) to evaluate these parameters to improve the clinical strategy. Nine FEA models with $0-\mathrm{mm}, 5-\mathrm{mm}$, and 10-mm posterior hook offsets implanted in the anterior, middle, and posterior acromion were established to evaluate the stress distribution and the reaction force on the acromion. The 5-mm and 10-mm posterior hook offsets at all acromion positions reduced the reaction force on the acromion but slightly increased the stress on the clavicle. The 0-mm offset increased the reaction force at all acromion positions and was relatively lower at the middle acromion. The clavicle hook plate with a posterior hook offset reduces the reaction force on the acromion, providing a flexibility of the hook position. These results provide surgeons with the biomechanical basis for the hook offset and position and engineers with the mechanical basis for the implant design.
\end{abstract}

Keywords: clavicle hook plate; hook offset; finite element analysis; acromioclavicular joint injury

\section{Introduction}

A clavicle hook plate is widely used to treat acromioclavicular dislocation and distal clavicle fracture [1-6], as its unique hook shape can provide a good stability and partial rotational mobility of the acromioclavicular joint [7]. Although it is a convenient, simple, and effective treatment $[5,6]$, some complications still occur, such as subacromial osteolysis [8-10], rotator cuff impingement [11], rotator cuff tear [11], and peri-implant fracture [10,12-15]. Furthermore, there is much variation in the anatomy of the acromion between individuals [16-19]. Nonetheless, biomechanical analysis has revealed many design parameters of the clavicle hook plate [20-22], and therefore, if an individualized clavicle hook plate designed for the patient's anatomy can be implanted, postoperative complications may be reduced [19,23-25].

A cadaver study indicated that the implantation position of the hook may be incorrect due to the wide range of anatomical acromion structures, possibly leading to subacromial osteolysis or rotator cuff impingement [16]. Another cadaver study indicated that the limited hook depth designs were not sufficient for acromion polymorphisms [17]. The relative position of the acromion and the hook is important, with an incorrectly positioned hook causing complications. At present, there is no clinical research or biomechanical 
analysis on the effect of the hook being fixed at different acromion positions in the acromioclavicular joint.

Finite element analysis (FEA) is commonly used to analyze orthopedic biomechanics, such as the biomechanics of the material and geometry of the clavicle hook plate. A longer plate length or a deeper hook depth can reduce the reaction force on the acromion, reducing the stress on the clavicle $[20,21]$, whereas a smaller hook angle increases the stress on the clavicle, and a larger hook angle increases the reaction force on the acromion [22]. Among the many clavicle hook plate designs, some of the posterior hook offset designs are different, but they have not been biomechanically evaluated in the acromioclavicular joint.

There is no relevant mechanical analysis research on the influence of the clavicle hook plate being fixed on the acromioclavicular joint at different acromion positions using various posterior hook offsets. Therefore, this study applied FEA for the biomechanical analysis of clavicle hook plates with different posterior hook offsets implanted at different acromion positions in the acromioclavicular joint and explored the possible causes of clinical subacromial osteolysis and peri-implant fracture. The orthopedic surgeon can select the clavicle hook plate that is suitable for the patient according to the different anatomical structures of the acromioclavicular joint, thereby minimizing surgical complications [10].

\section{Materials and Methods}

\subsection{The Simulation Geometry Model}

A computer model of FEA was established (Figure 1) comprising four parts including the clavicle, acromion, clavicle hook plate, and six screws. The model of the clavicle and acromion was built using computed tomography (CT) images provided by the US National Institutes of Health (NIH), and the medical image software Mimics (Mimics Medical 20.0, Materialise, Leuven, Belgium) was used to circle the clavicle and acromion on the CT image. The bone model was divided into two parts including the cortical bone and cancellous bone, with computer-aided design (CAD) software (SolidWorks 2016, Dassault Systemes SolidWorks Corp, Waltham, MA, USA) being used to obtain the model of the clavicle hook plate and six screws.

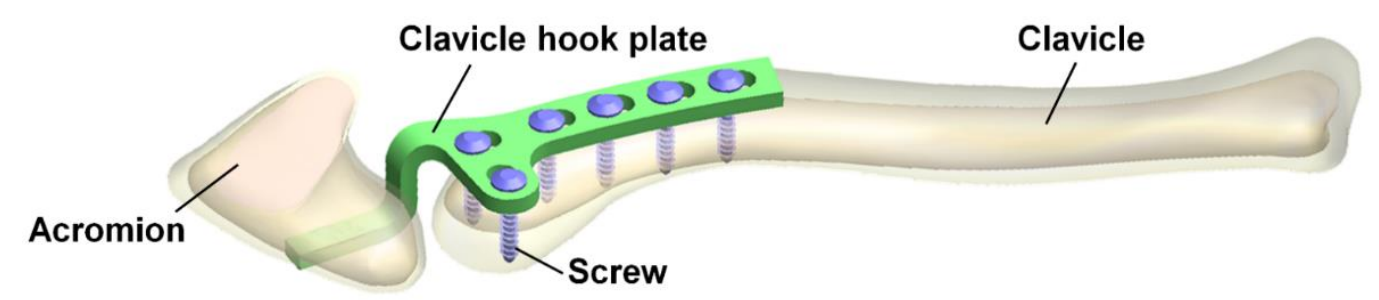

Figure 1. The four parts included the clavicle, acromion, clavicle hook plate, and six screws.

This study referred to the existing clinical clavicle hook plate system to establish three models of the clavicle hook plate with different posterior hook offsets. The offset sizes were $0 \mathrm{~mm}, 5 \mathrm{~mm}$, and $10 \mathrm{~mm}$ (Figure 2), and the hook was fixed on three different acromion positions including the anterior, middle, and posterior at an interval of $5 \mathrm{~mm}$; therefore, there were nine different sets (Figure 3). The CAD software SolidWorks was used to combine the clavicle, acromion, clavicle hook plate, and six screws, creating a total of nine sets of computer finite element models. After three-dimensional computer modeling, the models were imported into the FEA software (ANSYS Workbench 18.0, ANSYS, Inc., Canonsburg, PA, USA).

\subsection{Loading Conditions and Boundary Conditions}

One loading condition and two boundary conditions (Figure 4) were based on previous research measurements of the force on the sternocleidomastoid muscle when the arm picked up a cup [26] (The force of the loading condition was measured by the sternocleidomastoid muscle strength in the static position when the arm held the cup, which was established from the AnyBody Modeling System computer model with both the clavicle and 
acromion.). The loading condition was the upward-pull force on the medial clavicle with a sternocleidomastoid muscle attached (X-axis: $-1.5 \mathrm{~N}, \mathrm{Y}$-axis: $14.2 \mathrm{~N}$, Z-axis: $-4.2 \mathrm{~N})$. The boundary conditions defined the fixation of the inferior proximal clavicle and the inferior posterior acromion. The inferior proximal clavicle was fixed on a single point without displacement (i.e., the displacement of the X-axis, Y-axis, and Z-axis was set as zero); therefore, the clavicle could rotate when force was applied. The inferior posterior acromion was fixed to simulate the actual situation of a clavicle hook plate implanted in the acromioclavicular joint. In addition, to make this study closer to the actual situation, the contact between the clavicle hook plate and screws and between the clavicle hook plate and acromion was set as "no separation" in this study. The definition of "no separation" simulates a clavicle hook plate attached to the acromion surface with no gap existing between the two parts, but with a small amount of sliding being allowed [27].

\section{Posterior hook offset Posterior hook offset Posterior hook offset $0 \mathrm{~mm}$ $5 \mathrm{~mm}$ \\ $10 \mathrm{~mm}$}

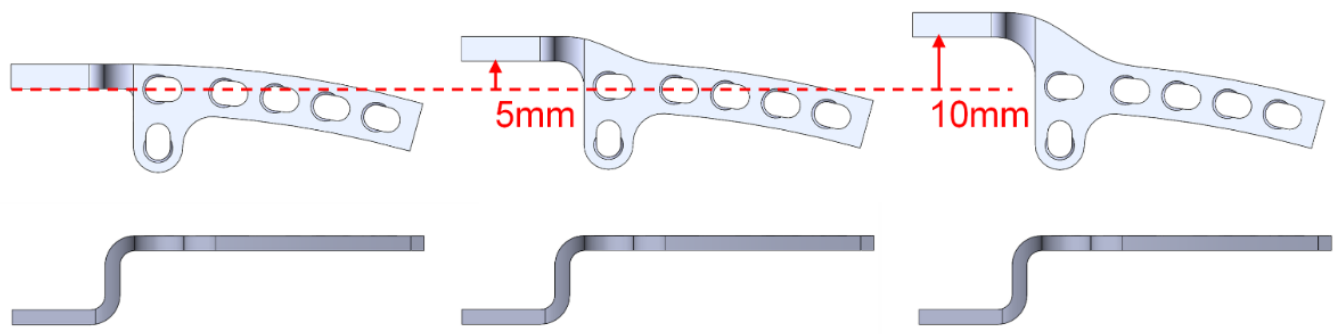

Figure 2. The posterior hook offsets were set at $0 \mathrm{~mm}, 5 \mathrm{~mm}$, and $10 \mathrm{~mm}$.

Three positions of the acromion
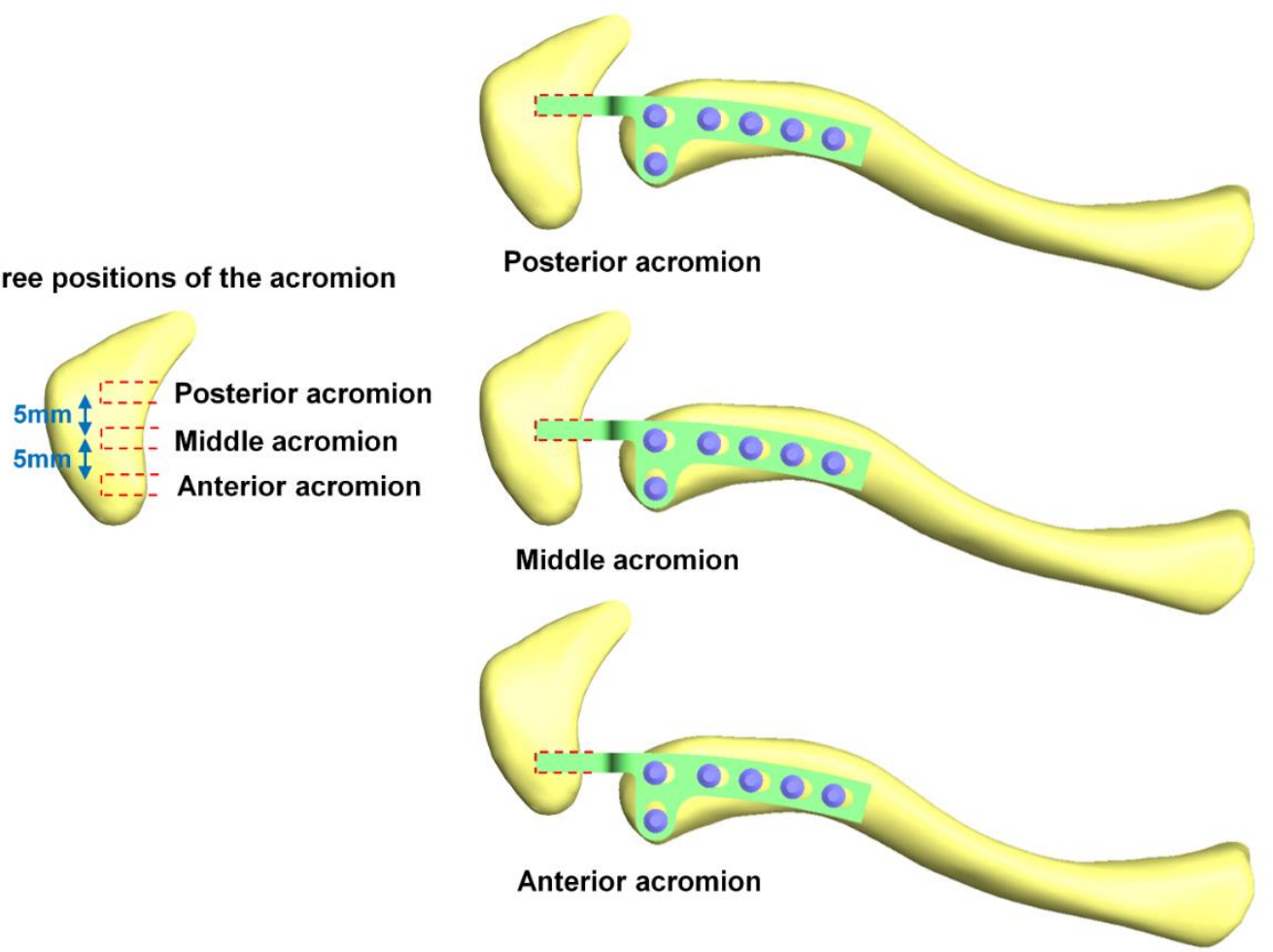

Figure 3. The hooks were fixed at the anterior, middle, and posterior of the acromion at an interval of $5 \mathrm{~mm}$.

\subsection{Material Properties of the Model}

The computer models comprised four parts including the clavicle, acromion, clavicle hook plate, and screws. All materials were assumed to be homogeneous, isotropic, and linear elastic. Table 1 shows the Young's modulus (E) and Poisson's ratio $(v)$ of the material 
properties. The mesh models were established using quadratic tetrahedral elements, with convergence tests to control the mesh size being performed to achieve convergence and more accurate data. The mesh size in this study was $0.9 \mathrm{~mm}$ (Figure 5), and Table 2 shows the number of elements and nodes in each group after mesh.

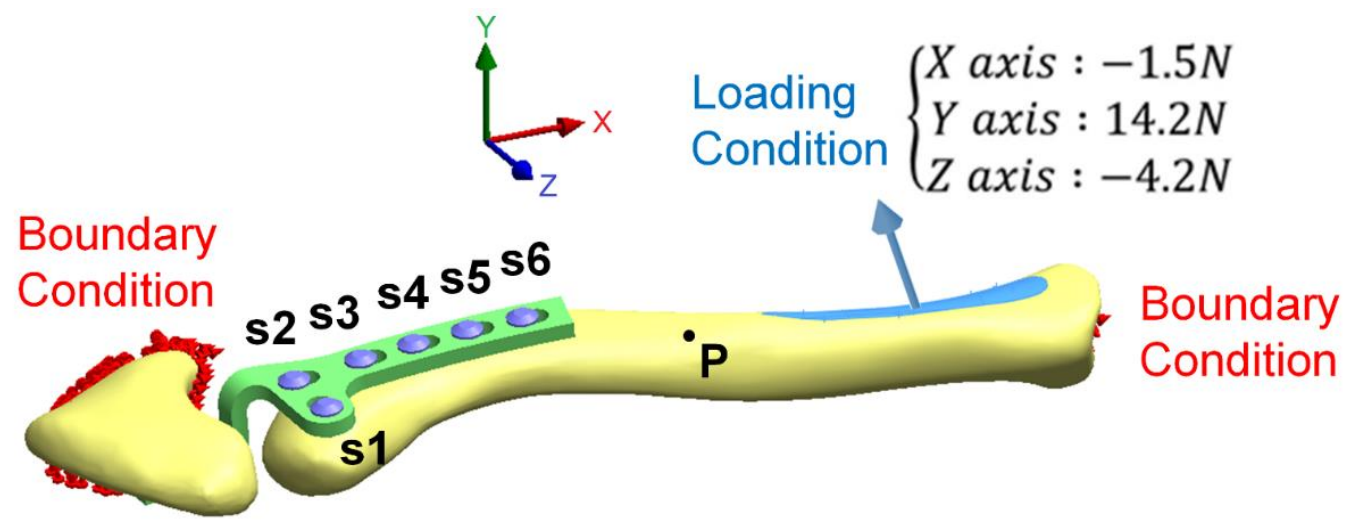

Figure 4. The loading conditions and boundary conditions in this study.

\subsection{Material Properties of the Model}

The computer models comprised four parts including the clavicle, acromion, clavicle hook plate, and screws. All materials were assumed to be homogeneous, isotropic, and linear elastic. Table 1 shows the Young's modulus (E) and Poisson's ratio $(v)$ of the material properties. The mesh models were established using quadratic tetrahedral elements, with convergence tests to control the mesh size being performed to achieve convergence and more accurate data. The mesh size in this study was $0.9 \mathrm{~mm}$ (Figure 5), and Table 2 shows the number of elements and nodes in each group after mesh.

Table 1. The material properties [20-22].

\begin{tabular}{ccc}
\hline Material & Young's Modulus (MPa) & Poisson's Ratio \\
\hline Cortical bone & 17,000 & 0.3 \\
Cancellous bone & 1000 & 0.3 \\
Clavicle hook plate & 200,000 & 0.3 \\
Screws & 118,000 & 0.3 \\
\hline
\end{tabular}
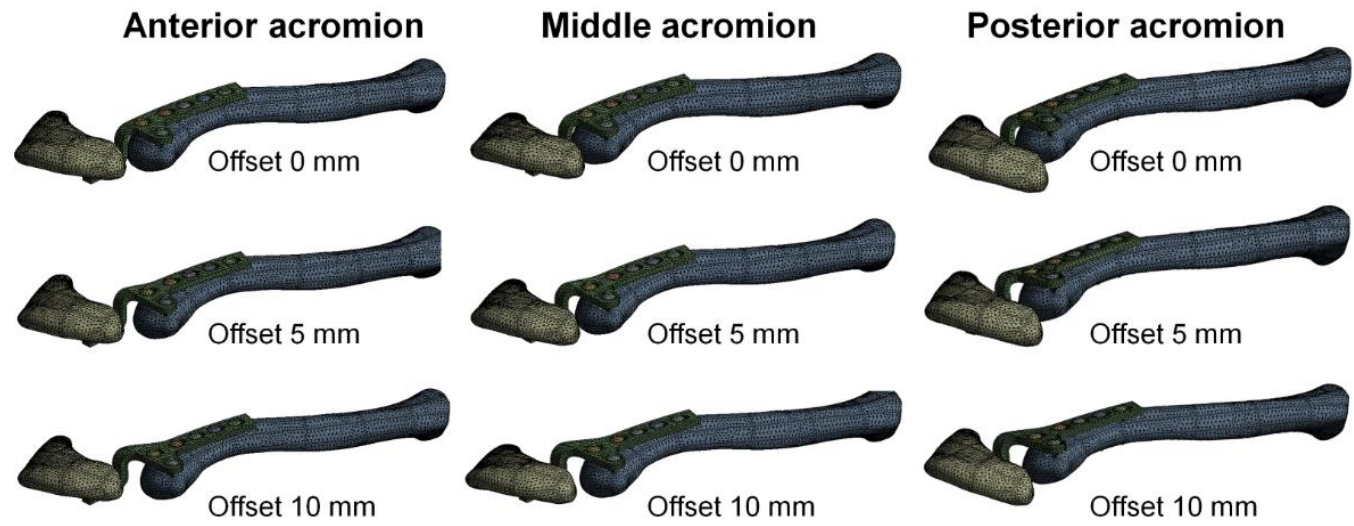

Figure 5. The mesh of the computer models used in this study.

After FEA, the von Mises stress distribution diagram was used as the observation index:

$$
\sigma_{\text {von }}=\sqrt{\frac{1}{2}\left[\left(\sigma_{1}-\sigma_{2}\right)^{2}+\left(\sigma_{1}-\sigma_{3}\right)^{2}+\left(\sigma_{2}-\sigma_{3}\right)^{2}\right]}
$$


where $\sigma 1, \sigma 2$, and $\sigma 3$ are the principal stresses in the three axial directions. The stress distribution diagram of the clavicle hook plate and the clavicle was observed, recording the stress on the six screws and at point $\mathrm{P}$ on the clavicle, the turning point of the mid-clavicle. The reaction force on the acromion after the external force was applied by the loading condition was also recorded.

Table 2. The number of elements and nodes in each group after mesh.

\begin{tabular}{|c|c|c|c|c|c|c|c|c|c|}
\hline \multirow[b]{2}{*}{$\begin{array}{c}\text { Posterior } \\
\text { Hook Offset }\end{array}$} & \multicolumn{3}{|c|}{ Anterior Acromion } & \multicolumn{3}{|c|}{ Middle Acromion } & \multicolumn{3}{|c|}{ Posterior Acromion } \\
\hline & $0 \mathrm{~mm}$ & $5 \mathrm{~mm}$ & $10 \mathrm{~mm}$ & $0 \mathrm{~mm}$ & $5 \mathrm{~mm}$ & $10 \mathrm{~mm}$ & $0 \mathrm{~mm}$ & $5 \mathrm{~mm}$ & $10 \mathrm{~mm}$ \\
\hline Mesh nodes & 188,882 & 190,086 & 191,971 & 188,217 & 189,421 & 191,445 & 188,467 & 189,553 & 191,507 \\
\hline Mesh elements & 103,576 & 104,296 & 105,362 & 103,171 & 103,889 & 105,064 & 103,335 & 103,983 & 105,102 \\
\hline
\end{tabular}

\section{Results}

The biomechanical effects of the clavicle hook plate with different posterior hook offsets implanted at various acromion positions were evaluated. Figure 6 shows the distribution of von Mises stress on the clavicle hook plate, with the greatest stress located at the corners of the hooks in all groups and a higher stress distributed on the part of the plates in the groups with a posterior hook offset. Figure 7 shows the distribution of von Mises stress on the clavicle, with the groups with posterior hook offsets generating a higher stress on the clavicle. Figure 8 shows the reaction force on the acromion, showing that groups without a posterior hook offset generated a greater reaction force on the acromion. Table 3 shows the value of the reaction force on the acromion and the stress on the clavicle hook plate, each screw, and at point $\mathrm{P}$ of the clavicle.

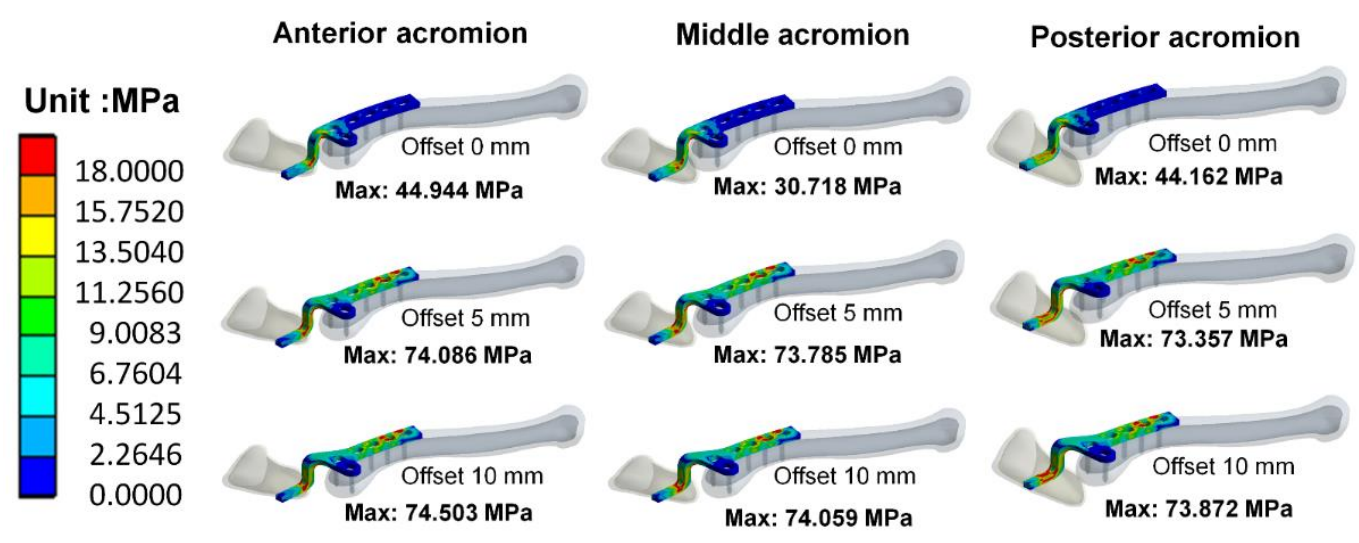

Figure 6. The distribution of von Mises stress on the clavicle hook plate.

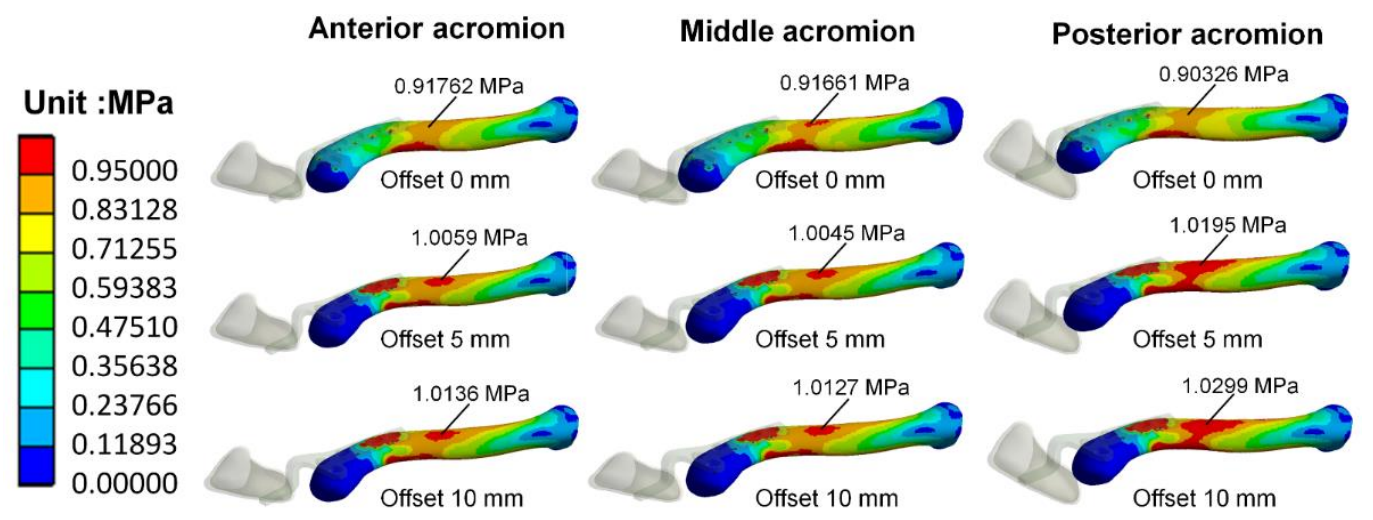

Figure 7. The distribution of von Mises stress on the clavicle. 


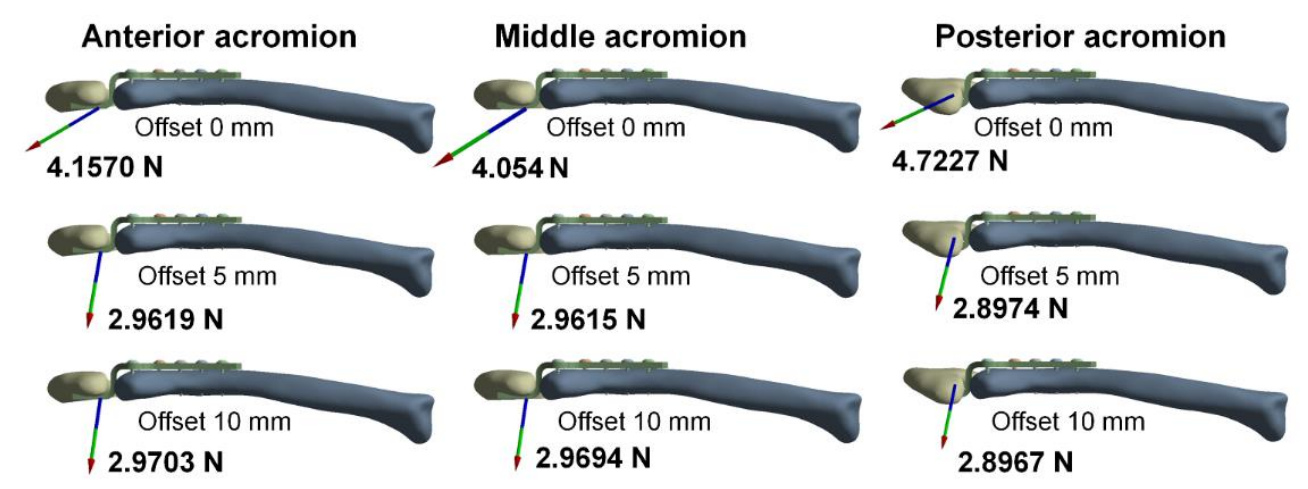

Figure 8. The reaction force on the acromion.

Table 3. The reaction force on the acromion and the stress on the clavicle hook plate, each screw, and at point P of the clavicle.

\begin{tabular}{|c|c|c|c|c|c|c|c|c|c|c|}
\hline \multirow{2}{*}{\multicolumn{2}{|c|}{$\begin{array}{c}\text { Hook Position } \\
\text { Posterior Hook Offset }\end{array}$}} & \multicolumn{3}{|c|}{ Anterior Acromion } & \multicolumn{3}{|c|}{ Middle Acromion } & \multicolumn{3}{|c|}{ Posterior Acromion } \\
\hline & & $0 \mathrm{~mm}$ & $5 \mathrm{~mm}$ & $10 \mathrm{~mm}$ & $0 \mathrm{~mm}$ & $5 \mathrm{~mm}$ & $10 \mathrm{~mm}$ & $0 \mathrm{~mm}$ & $5 \mathrm{~mm}$ & $10 \mathrm{~mm}$ \\
\hline \multirow{4}{*}{$\begin{array}{l}\text { Reaction force } \\
\text { on acromion }(\mathrm{N})\end{array}$} & X-Axis & -3.5615 & -0.4431 & -0.37351 & -3.4105 & -0.4572 & -0.38434 & -4.2696 & -0.62777 & -0.50583 \\
\hline & Y-Axis & -2.1026 & -2.5631 & -2.5622 & -2.1436 & -2.5634 & -2.562 & -2.0026 & -2.4803 & -2.4812 \\
\hline & Z-Axis & 0.4186 & 1.4168 & 1.4555 & 0.45633 & 1.4107 & 1.4511 & 0.25256 & 1.3597 & 1.4068 \\
\hline & Total & 4.157 & 2.9619 & 2.9703 & 4.054 & 2.9615 & 2.9694 & 4.7227 & 2.8974 & 2.8967 \\
\hline \multirow{8}{*}{$\begin{array}{l}\text { Maximum stress } \\
(\mathrm{MPa})\end{array}$} & Plate & 44.944 & 74.086 & 74.503 & 30.718 & 73.785 & 74.059 & 44.162 & 73.357 & 73.872 \\
\hline & S1 & 2.6561 & 0.17302 & 0.17333 & 2.0829 & 0.17919 & 0.18024 & 2.6496 & 0.18685 & 0.18839 \\
\hline & $\mathrm{S} 2$ & 2.0644 & 5.3123 & 5.3011 & 1.8372 & 5.3895 & 5.5165 & 1.9973 & 5.5796 & 5.5942 \\
\hline & S3 & 3.9743 & 16.426 & 16.46 & 4.7258 & 17.008 & 17.123 & 5.2918 & 17.813 & 17.978 \\
\hline & S4 & 9.4925 & 32.812 & 32.778 & 11.137 & 34.008 & 34.102 & 12.17 & 35.307 & 35.463 \\
\hline & S5 & 1.7393 & 6.7224 & 6.7844 & 1.998 & 6.9667 & 7.0806 & 2.206 & 7.4543 & 7.5953 \\
\hline & S6 & 10.331 & 33.743 & 33.689 & 11.943 & 35.022 & 35.112 & 13.181 & 36.512 & 36.674 \\
\hline & Point $\mathrm{P}$ & 0.91762 & 1.0059 & 1.0136 & 0.91661 & 1.0045 & 1.0127 & 0.90326 & 1.0195 & 1.0299 \\
\hline
\end{tabular}

\section{Discussion}

This FEA study explored the biomechanical effects of different posterior hook offsets of clavicle hook plates implanted at various acromion positions. The reaction force on the acromion was greater in the groups without a posterior hook offset and lower in the groups with posterior hook offsets, with the groups with 5-mm or 10-mm offsets showing a similar reaction force. The different reaction forces are attributed to the increased lever arm length in the clavicle hook plate with a posterior hook offset when compared to those without an offset. The fulcrum was set at the fixed point of the proximal clavicle, and the lever arm length was measured between the fulcrum and the contact point of the acromion and hook (Figure 9); therefore, the larger the posterior hook offset, the longer the lever arm, thereby resulting in a smaller reaction force on the acromion. The clavicle hook plate with the posterior hook offset reduces the reaction force by $26.75-38.66 \%$ on the acromion when compared to the one without a posterior hook offset.

The stress on the mid-third clavicle was lower in the groups without a posterior hook offset and greater in the groups with a posterior hook offset, with groups with a 5-mm or 10-mm offset exhibiting similar stress. This is assumed to be due to the distance between the hook fixed on the acromion and the proximal clavicle becoming longer in the clavicle hook plate with a posterior hook offset than in the one without. When the same force is applied, the longer distance leads to a larger deformation of the mid-third clavicle. Strain is related to deformation, and the Young's modulus of the clavicle in all of the groups in this study was constant; therefore, the larger the deformed clavicle in the groups with a posterior hook offset, the greater the strain and the stress on the clavicle. Clinically, the high-stress distribution on the clavicle may correlate with the high incidence of peri-implant fractures in the mid-third clavicle [20-22]. 


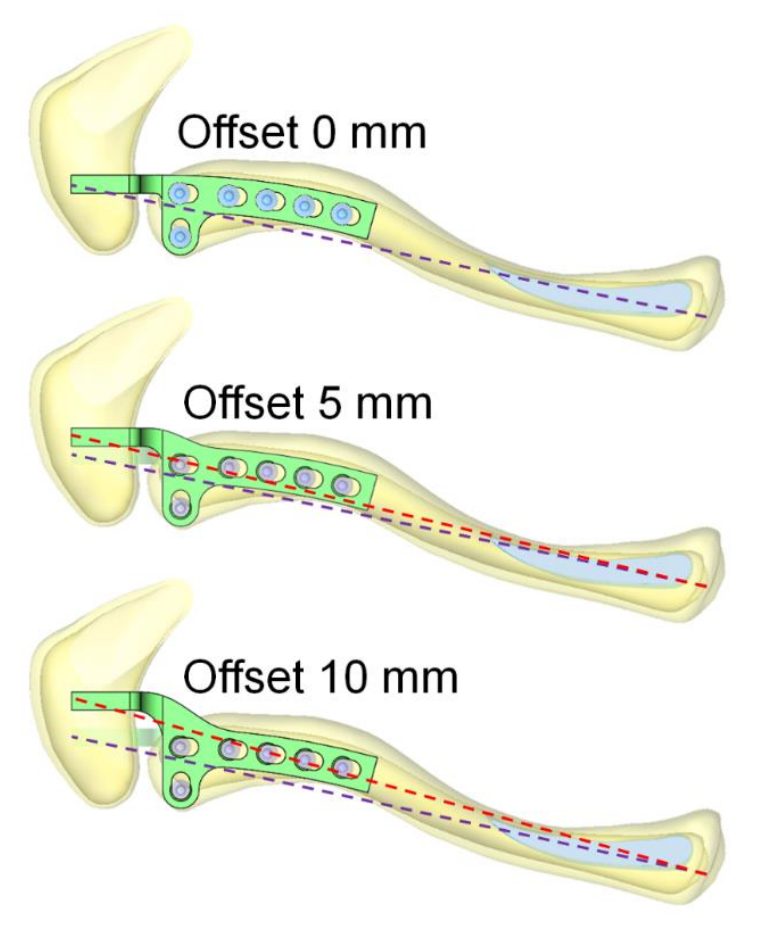

Figure 9. The existence of a posterior hook offset increases the lever arm length, resulting in a smaller reaction force on the acromion.

Based on the above analysis, the existence of a posterior hook offset is the key variable of this mechanical analysis. The clavicle hook plate without a posterior hook offset has a greater reaction force on the acromion but less stress on the mid-third of the clavicle, which may increase the probability of subacromial osteolysis $[8,9,13]$. The clavicle hook plate with a posterior hook offset has less reaction force on the acromion but greater stress on the mid-third of the clavicle, which may increase the risk of peri-implant fracture $[10,12,13]$.

The reaction force analysis of the different posterior hook offsets fixed at the anterior, middle, and posterior acromion shows that the groups without a posterior hook offset have a higher reaction force on the acromion than the groups with a posterior hook offset. In the group without a posterior hook offset, the hook fixed at the middle acromion exhibits a relatively lower reaction force on the acromion, whereas in the groups with a posterior hook offset, the hook fixed in three different positions causes little difference in the reaction force. There is a little difference in the reaction force at different fixed positions of the hook in the acromion, which can be explained biomechanically. The distance from the fixed end of the acromion to the hook fixed in the acromion can be used as a factor to discuss the change in the reaction force. However, for the overall structure, the differences in the distance between the hooks fixed in the anterior acromion, middle acromion, and posterior acromion are tiny when compared with the overall structure. Therefore, there is a little difference between the results on this factor. Clinically, using a clavicle hook plate with a posterior hook offset is more flexible and tolerant for fixing it at any acromion position during surgery in order to reduce the reaction force on the acromion. If a clavicle hook plate without a posterior hook offset is used, hook fixation at the middle acromion is recommended if space permits it.

The greatest stress was located on the bend of the hook plate in contact with the acromion in all groups. In the groups with a posterior hook offset, the stress was also distributed on part of the plate, indicating that the shape of the posterior hook offset may cause a larger deformation in the plate of the clavicle hook plate, leading to greater stress on the plate according to Hooke's law. However, the maximum stress in all models was less than the yield strength of the material of the clavicle hook plate, with the yield strength of stainless steel and titanium being $700 \mathrm{MPa}$ and $490 \mathrm{MPa}$, respectively [28]. Hence, if a 
higher stress is located on the hook corner and the plate, deformation or fracture of the implants rarely occurs.

Regarding the stress on the six screws in the clavicle, the highest stress was located on the innermost screw (S6) in all groups. The groups without a posterior hook offset experienced less stress, whereas the groups with a posterior hook offset had greater stress. Although the stress on the innermost screw was less than the yield strength of the bone, the innermost screw must be placed carefully in order to avoid high stress on the clavicle that may increase the risk of peri-implant fracture, especially for the clavicle hook plate with a posterior hook offset.

This study has several limitations. The model simulates an acromioclavicular joint with an implanted clavicle hook plate which assumes that the acromioclavicular ligament and coracoclavicular ligament are total torn, so the external force is only applied to the sternocleidomastoid muscle. Since this study only discusses the biomechanical analysis of the clavicle hook plate, acromioclavicular joint, and clavicle, the scapula model was simplified to the acromion only. Due to the anatomic differences among individuals, verifying the models with the computer research data established in this study and other previous research data was difficult. This study only selected representative bone models for analysis. Therefore, only the computer models established in this study were verified by a mesh convergence test. In addition, the material properties are assumed to be homogeneous, isotropic, and linearly elastic based on the assumptions of previous studies [20-22]. Although we also wanted to use anisotropic material properties to set the bone tissue, the finite element analysis of nonlinear material properties was challenging to solve. Therefore, it was possible that the nonlinear material setting used in this study could lead to more influencing factors for the topic discussed in this study. Thus, this study simplified the establishment of computer models and material properties, mainly to make biomechanical evaluations for the main issues discussed in this study so as to avoid too many factors that affect the results of computer simulation studies. Given the experimental design of this study, it was indeed unable to prove directly that variations in the posterior hook offset led to peri-implant fracture or subacromial osteolysis; however, this study can still explain that the posterior hook offset made the biomechanical difference in the strain on the clavicle. Although these assumptions are slightly different from the actual situation, this study evaluated the biomechanical trends of the implantation of clavicle hook plates with different posterior hook offsets at various positions in the acromion.

This FEA of the biomechanical impact of a clavicle hook plate with different posterior hook offsets fixed at various acromion positions provides the basis for a new-design clavicle hook plate, as well as a clearer understanding of the posterior hook offset design of the clavicle hook plate. It is anticipated that clavicle hook plates specific to each patient can be used to get better stress and reaction force distributions on the acromioclavicular joint $[10,19,23-25,29]$. The research on the hook plate with posterior hook offset involves not only the biomechanical effect but also the patient's subjective feeling with different hook offset implantations. This might be interesting for clinical research in the future.

\section{Conclusions}

The clavicle hook plate without a posterior hook offset increases the reaction force of the hook to the acromion, which may lead to subacromial osteolysis. In contrast, the clavicle hook plate with a posterior hook offset reduces the reaction force of the hook to the acromion, slightly increasing the stress on the mid-third of the clavicle, which may increase the risk of peri-implant fracture. The hook with a posterior offset has a lower reaction force at any position in the acromion, so there is more flexibility in the surgeon's placement of the implant to reduce the reaction force on the acromion. The hook without a posterior offset exhibits a large reaction force on the acromion, so fixation in the middle acromion is recommended if space permits it. These results provide orthopedic surgeons with the biomechanical basis for the selection of an appropriate clavicle hook plate design and implantation position. 
Author Contributions: Conceptualization, L.-K.H. and C.-H.L.; methodology, K.-C.S.; data curation, L.-K.H. and K.-C.S.; writing-original draft preparation, L.-K.H. and C.-H.L.; writing-review and editing, L.-K.H. and K.-C.S. All authors have read and agreed to the published version of the manuscript.

Funding: This research received no external funding.

Institutional Review Board Statement: Not applicable.

Informed Consent Statement: Not applicable.

Data Availability Statement: Not applicable.

Acknowledgments: The authors acknowledge the United States National Library of Medicine (NLM) and the Visible Human Project as the image source for building the finite element analysis models in this study. We appreciate Taichung Veterans General Hospital (TCVGH-1087320C, TCVGH-1107315C, TCVGH-HK1098002 and TCVGH-1105101C) in Taiwan for supporting this research, and the 3D Printing Research and Development Group of Taichung Veterans General Hospital for building these simulation geometry models. The authors Li-Kun Hung and Cheng-Hung Lee contributed equally to this work.

Conflicts of Interest: The authors declare no conflict of interest.

\section{References}

1. Di Francesco, A.; Zoccali, C.; Colafarina, O.; Pizzoferrato, R.; Flamini, S. The use of hook plate in type III and V acromio-clavicular Rockwood dislocations: Clinical and radiological midterm results and MRI evaluation in 42 patients. Injury 2012, 43, 147-152. [CrossRef]

2. Tiren, D.; van Bemmel, A.J.; Swank, D.J.; van der Linden, F.M. Hook plate fixation of acute displaced lateral clavicle fractures: Mid-term results and a brief literature overview. J. Orthop. Surg. Res. 2012, 7, 2. [CrossRef]

3. Kumar, N.; Sharma, V. Hook plate fixation for acute acromioclavicular dislocations without coracoclavicular ligament reconstruction: A functional outcome study in military personnel. Strategies. Trauma. Limb. Reconstr. 2015, 10, 79-85. [CrossRef] [PubMed]

4. Baunach, D.; Eid, K.; Ricks, M.; Borbas, P. Long-term clinical and radiological results after hook plate osteosynthesis of lateral clavicle fractures. J. Orthop. Trauma. 2021, 35, 378-383. [CrossRef] [PubMed]

5. Yoon, B.; Kim, J.Y.; Lee, J.-S.; Jung, H.S. The Radiologic Comparison of Operative Treatment Using a Hook Plate versus a Distal Clavicle Locking Plate of Distal Clavicle Fracture. Clin. Shoulder Elb. 2018, 21, 227-233. [CrossRef] [PubMed]

6. Hemmann, P.; Koch, M.; Guehring, M.; Bahrs, C.; Ziegler, P. Acromioclavicular joint separation treated with clavicular hook plate: A study of radiological and functional outcomes. Arch. Orthop. Trauma. Surg. 2021, 141, 603-610. [CrossRef] [PubMed]

7. Kim, Y.S.; Yoo, Y.-S.; Jang, S.W.; Nair, A.V.; Jin, H.; Song, H.-S. In vivo analysis of acromioclavicular joint motion after hook plate fixation using three-dimensional computed tomography. J. Shoulder Elb. Surg. 2015, 24, 1106-1111. [CrossRef]

8. Hoffler, C.E.; Karas, S.G. Transacromial erosion of a locked subacromial hook plate: Case report and review of literature. J. Shoulder Elb. Surg. 2010, 19, e12-e15. [CrossRef]

9. Chiang, C.-L.; Yang, S.-W.; Tsai, M.-Y.; Chen, C.K.-H. Acromion osteolysis and fracture after hook plate fixation for acromioclavicular joint dislocation: A case report. J. Shoulder Elb. Surg. 2010, 19, e13-e15. [CrossRef]

10. Lopiz, Y.; Checa, P.; García-Fernández, C.; Valle, J.; Vega, M.L.; Marco, F. Complications with the clavicle hook plate after fixation of Neer type II clavicle fractures. Int. Orthop. 2019, 43, 1701-1708. [CrossRef]

11. Lin, H.-Y.; Wong, P.-K.; Ho, W.-P.; Chuang, T.-Y.; Liao, Y.-S.; Wong, C.-C. Clavicular hook plate may induce subacromial shoulder impingement and rotator cuff lesion-dynamic sonographic evaluation. J. Orthop. Surg. Res. 2014, 9, 1-9. [CrossRef] [PubMed]

12. Charity, R.M.; Haidar, S.G.; Ghosh, S.; Tillu, A.B. Fixation failure of the clavicular hook plate: A report of three cases. J. Orthop. Surg. 2006, 14, 333-335. [CrossRef]

13. Ding, M.; Ni, J.; Hu, J.; Song, D. Rare complication of clavicular hook plate: Clavicle fracture at the medial end of the plate. J. Shoulder Elb. Surg. 2011, 20, e18-e20. [CrossRef] [PubMed]

14. Ni, P.-L.; Lin, K.-C.; Chen, C.-Y.; Tarng, Y.-W.; Chang, W.-N.; Renn, J.-H. Peri-implant Fractures Following Hook Plate Fixation for Unstable Distal Clavicle Fractures. Orthopedics 2020, 43, e359-e363. [CrossRef] [PubMed]

15. Shih, J.-T.; Wu, C.-C.; Wang, C.-C.; Yeh, T.-T.; Pan, R.-Y.; Chen, C.-L.; Chien, W.-C.; Shen, P.-H. Midshaft clavicle fracture following osteosynthesis with a hook plate: A retrospective case analysis. Arch. Orthop. Trauma Surg. 2020, 140, 1713-1718. [CrossRef]

16. ElMaraghy, A.W.; Devereaux, M.W.; Ravichandiran, K.; Agur, A.M. Subacromial morphometric assessment of the clavicle hook plate. Injury 2010, 41, 613-619. [CrossRef]

17. Deng, Z.; Cai, L.; Ping, A.; Ai, Q.; Wang, Y. Anatomical research on the subacromial interval following implantation of clavicle hook plates. Int J. Sports Med. 2014, 35, 857-862. [CrossRef] 
18. Shen, P.-C.; Zhu, Y.; Zhang, H.; Zhu, L.-F.; Weng, F.-B.; Jiang, F.-G.; Xu, N.; Ju, W.; Li, X.-L. Three-dimensional morphological analysis of acromioclavicular joint in patients with and without subacromial erosion after hook plate fixation. J. Int. Med. Res. 2018, 46, 511-521. [CrossRef]

19. Kim, S.-J.; Kee, Y.-M.; Park, D.-H.; Ko, Y.-I.; Lee, B.-G. Evaluation of the Acromioclavicular Joint Morphology for Minimizing Subacromial Erosion after Surgical Fixation of the Joint Using a Clavicular Hook Plate. Clin. Shoulder Elb. 2018, 21, 138-144. [CrossRef]

20. Lee, C.-H.; Shih, C.-M.; Huang, K.-C.; Chen, K.-H.; Hung, L.-K.; Su, K.-C. Biomechanical analysis of implanted clavicle hook plates with different implant depths and materials in the acromioclavicular joint: A finite element analysis study. Artif. Organs. 2016, 40, 1062-1070. [CrossRef]

21. Shih, C.-M.; Huang, K.-C.; Pan, C.-C.; Lee, C.-H.; Su, K.-C. Biomechanical analysis of acromioclavicular joint dislocation treated with clavicle hook plates in different lengths. Int. Orthop. 2015, 39, 2239-2244. [CrossRef] [PubMed]

22. Hung, L.-K.; Su, K.-C.; Lu, W.-H.; Lee, C.-H. Biomechanical analysis of clavicle hook plate implantation with different hook angles in the acromioclavicular joint. Int. Orthop. 2017, 41, 1663-1669. [CrossRef]

23. Wu, K.; Su, X.; Roche, S.J.L.; Held, M.F.G.; Yang, H.; Dunn, R.N.; Guo, J.J. Relationship between the lateral acromion angle and postoperative persistent pain of distal clavicle fracture treated with clavicle hook plate. J. Orthop. Surg. Res. 2020, 15, 217. [CrossRef] [PubMed]

24. Li, G.; Liu, T.; Shao, X.; Liu, Z.; Duan, J.; Akileh, R.; Cao, S.; Jin, D. Fifteen-degree clavicular hook plate achieves better clinical outcomes in the treatment of acromioclavicular joint dislocation. J. Int. Med. Res. 2018, 46, 4547-4559. [CrossRef]

25. Qiao, R.; Yang, J.; Zhang, K.; Song, Z. To explore the reasonable selection of clavicular hook plate to reduce the occurrence of subacromial impingement syndrome after operation. J. Orthop. Surg. Res. 2021, 16, 180. [CrossRef] [PubMed]

26. Cronskär, M.; Rasmussen, J.; Tinnsten, M. Combined finite element and multibody musculoskeletal investigation of a fractured clavicle with reconstruction plate. Comput. Methods Biomech. Biomed. Eng. 2015, 18, 740-748. [CrossRef]

27. Lee, H.H. Finite Element Simulations with ANSYS Workbench 15; Chuan Hwa Book Co.: Taiwan, 2014.

28. Enderle, J.; Bronzino, J. Introduction to Biomedical Engineering; Academic Press: Boston, MA, USA, 2012.

29. Wu, D.-K.; Chen, W.-C.; Lin, K.-J.; Tsai, C.-L.; Lin, K.-P.; Wei, H.-W. Advantage of Multi-Directional Stability of Spiral Clavicle Plate in Treatment of Middle One-Third Clavicle Fracture: A Finite Element Study. J. Med. Biol. Eng. 2021, 41, 405-411. [CrossRef] 